\title{
The modified Atkins diet in children with Prader-Willi syndrome
}

\author{
Grace Felix ${ }^{1,2}$, Eric Kossoff ${ }^{3}$, Bobbie Barron ${ }^{4}$, Caitlin Krekel ${ }^{4}$, Elizabeth Getzoff Testa ${ }^{5}$ and Ann Scheimann ${ }^{1,6^{*}}$
}

\begin{abstract}
Background: Prader-Willi Syndrome (PWS) is the most common genetic cause of obesity. Various dietary strategies have been used for weight management for people with PWS.

Methods: This was a clinical feasibility study to test the use of the Modified Atkins Diet (low carbohydrate and high fat) for children with PWS ages 6-12 years who were overweight/obese. Participants went on the Modified Atkins Diet for 4 months and then returned to have anthropometry repeated including repeat labs and behavior questionnaires.

Results: Seven children (ages 6-12) were enrolled in the study. Four participants completed the 4-month diet trial; two were unable to comply with the diet and stopped prematurely. One patient lost $2.9 \mathrm{~kg}$; the others maintained their weight. Adverse effects were increases in LDL (expected based on larger studies) and hypercalciuria (with no renal stones) for one patient. Positive effects on hyperphagia and behavior were noted subjectively by families.

Conclusion: The Modified Atkins Diet can be a feasible low carbohydrate option for children with Prader-Willi Syndrome for weight management. Long-term use of the diet in patients with Prader-Willi Syndrome needs to be studied further.
\end{abstract}

Keywords: Prader-Willi syndrome, Pediatric obesity, Obesity, Diet, Low-carbohydrate diet, Ketogenic

\section{Introduction}

Prader-Willi Syndrome (PWS) is the most common genetic cause of obesity caused by mutations in the paternal genes on chromosome 15q11-q13. In the 20 years after this syndrome was first described by Drs. Prader and Willi in 1956, its incidence was estimated to be 1 in 25 , 000 births. However, with earlier and increased diagnosis, it is now thought that the incidence is closer to 1 in $15,000[1,2]$. Classically, it presents in infancy with the combination of hypotonia, feeding problems, failure to thrive, developmental delay, and hypogonadism/hypogenitalism [3, 4] During childhood, patients develop

\footnotetext{
* Correspondence: ascheima@jhmi.edu

'Division of Pediatric Gastroenterology and Nutrition, Johns Hopkins School of Medicine, Baltimore, MD, USA

${ }^{6}$ Division of Pediatric Gastroenterology and Nutrition, Johns Hopkins Hospital, 600 N. Wolfe Street Brady 320, Baltimore, MD 21287-2631, USA

Full list of author information is available at the end of the article
}

insatiable appetite, hyperphagia and obesity. Mild learning impairment and behavioral problems are also noted including self-injury, obsessive-compulsive disorder, anxiety, and temper tantrums.

Families of children with PWS have reported that weight and behavior issues are of greatest concern. In the 1970s, the protein-sparing modified fast became in use for children with Prader-Willi Syndrome; this diet consisted of $1.5 \mathrm{~g}$ of meat protein per kilogram of ideal weight per day, supplemented with low-carb, low-fat foods/drinks [5-11]. More recently, there is also the often used "Red Yellow Green" Weight Management system for children with Prader-Willi Syndrome that emphasizes a balanced diet and avoidance of highcalorie, high-fat foods in addition to environmental control measures [12] .

However, with ketogenic and low carbohydrate diets gaining much interest in the mainstream population, 
and widely used for refractory pediatric epilepsy, anecdotal reports that this diet was helpful among people with Prader-Willi Syndrome in regards to hyperphagia and weight control surfaced. This study used the Modified Atkins Diet (MAD), which is less restrictive than the classic ketogenic diet used in pediatric epilepsy. MAD allows up to $10-15 \mathrm{~g}$ of net carbohydrates (total minus fiber) per day for children, and protein and fat is either unrestricted or can be individualized to achieve ketosis [13-15].

In 2016, the Charlie Foundation and the TREND Community enrolled 14 patients with PWS ages 2 through 11, to complete a modified ketogenic diet for 6 months and report labs and family input on behavior and appetite back to the TREND database [16]. Ten patients completed the 6-month duration of the diet and 4 were unable to due to reasons besides ineffectiveness of the diet. Of those that completed the diet, all 10 participants and families noted positive impact on behavioral/ cognitive function, and/or hyperphagia and all of these families continued the diet beyond the study's 6 month period.

This feasibility study is a prospective study that enrolled children with PWS to complete a 4-month trial of the Modified Atkins Diet, and studied weight changes, laboratory markers, tolerability of the diet and subjective behavioral changes.

\section{Methodology}

This study was approved by the Institutional Review Board at Johns Hopkins University School of Medicine. This was a pilot and feasibility study investigating the Modified Atkins Diet for children with Prader-Willi Syndrome. It was funded by the Foundation of PraderWilli Research, Canada and a NIH T32 Training Grant. Children ages 6-12 years with genetically confirmed PWS were recruited. Recruitment was done through offering study participation to patients of the principal investigator and social media advertising on the Foundation for Prader-Willi Research page. Breakfast and lunch were provided for the day of study visits for the participant. Travel costs were reimbursed for out-ofstate participant families to help offset financial burden. Consent from parents and assent from children were obtained. Study visits were conducted at the Johns Hopkins Hospital Pediatric Clinical Research Unit in Baltimore, Maryland, USA. Participants were excluded from the study if they had a history of hyperlipidemia, multiple food allergies, significant GI dysmotility, or hypercalciuria.

Total study duration was approximately 12 months per participant, with 4 months being on the diet and 4 months being off the diet and an initial teaching session. The study design consisted of three study visits, 4 months apart, at the study site for each participant. At each visit, participants met with the study physician, research dietitian and study psychologist. Each visit consisted of updated history, anthropometry, fasting blood work (comprehensive metabolic panel, lipid profile, hemoglobin $\mathrm{A} 1 \mathrm{C}$, insulin level), urine studies (urinalysis, urine calcium, urine creatinine), and psychology questionnaires. Families and participants were also asked to comment subjectively on behavior, skin picking, and hyperphagia by the study psychologist or study physician.

At the first study visit, the research dietitian met with study participants and their caregivers for a $2 \mathrm{~h}$ teaching session on how to implement the study diet and track urine ketones; recipes and sample menus were provided. Study participants were instructed to follow a $10-15 \mathrm{~g}$ net carbohydrate limit (a calculation of total carbohydrates minus fiber), to take a general pediatric multivitamin with minerals, a vitamin $\mathrm{D}$ supplement (600 international units - IU) daily, and a calcium supplement $(1000 \mathrm{mg} /$ day for $4-8$ years olds and $1300 \mathrm{mg} /$ day for $9-13$ years olds). Protein and fat guidance was provided on an individual basis. Hydration was encouraged.

A power calculation and statistical analysis was not done due to small sample size. The statistics reported are descriptive. The goal of this study was feasibility and it was acknowledged that we would not have the numbers needed to gain statistical power of this data.

\section{Results}

Table 1 shows the basic demographic and clinical information for patients enrolled. Seven participants, age 6-12, with genetically confirmed PWS were enrolled in the study. All except one had a BMI greater than the 95th percentile, but with a considerable range in BMI from $16.7 \mathrm{~kg} / \mathrm{m} 2$ to $61.9 \mathrm{~kg} / \mathrm{m} 2$ (height data not shown).

Figure 1 explains the flowchart of participants who were enrolled in the study and able to complete the study and exceptions. Two participants were unable to comply with the diet and did not complete the diet. For example, one of these participants attempted the diet while at home but was still having regular school lunches including juice and milk daily. There were also several social stressors for the family at the time. The second participant that was unable to do the diet essentially never started due to family's difficulty to plan meals and have "allowable foods" available and have all caregivers in the family on board with the diet. One participant had an elevated urine calcium/creatinine ratio prior to the start of the diet so the patient was excluded per protocol. In total, four participants completed the full 4-month diet trial and study. 
Table 1 Clinical Characteristics of Study Participants

\begin{tabular}{lllllll}
\hline Participant No. & Age (years) & Sex & Ethnicity & BMI & BMl \% & $\begin{array}{l}\text { Genetic } \\
\text { Basis }\end{array}$ \\
\hline $\mathbf{1}$ & 12.6 & F & White & 23.9 & $95 \%$ & Uniparental Disomy \\
$\mathbf{2}$ & 8.1 & F & White & 22.5 & $97 \%$ & Chromosomal Deletion \\
$\mathbf{3}$ & 8.9 & F & Asian & 28.9 & $99 \%$ & Chromosomal Deletion \\
$\mathbf{4}$ & 7.1 & F & White & 21.5 & $97 \%$ & Uniparental Disomy \\
$\mathbf{5}$ & 6.0 & M & White & 16.7 & $78 \%$ & Uniparental Disomy \\
$\mathbf{6}$ & 7.6 & F & Black & 30.8 & $99 \%$ & Chromosomal Deletion \\
$\mathbf{7}$ & 12.6 & M & Black & 61.9 & $>99 \%$ & Chromosomal Deletion \\
\hline
\end{tabular}

Participants who did complete the diet reported that it was tolerable and parents saw drastic changes in their child's attitude toward food. Parents reported that children were not as obsessed about the "next snack or the next meal." One parent recalled an example: at a birthday party, one participant took "only $1 / 4$ of a minicupcake to eat at a later time; something that she would never have done before". They stated that frequency of temper tantrums and moodiness was "much improved". Parents were hesitant to stop the diet at the end of the 4-month period due to these improvements despite the need for meal planning and initial challenges of the diet.

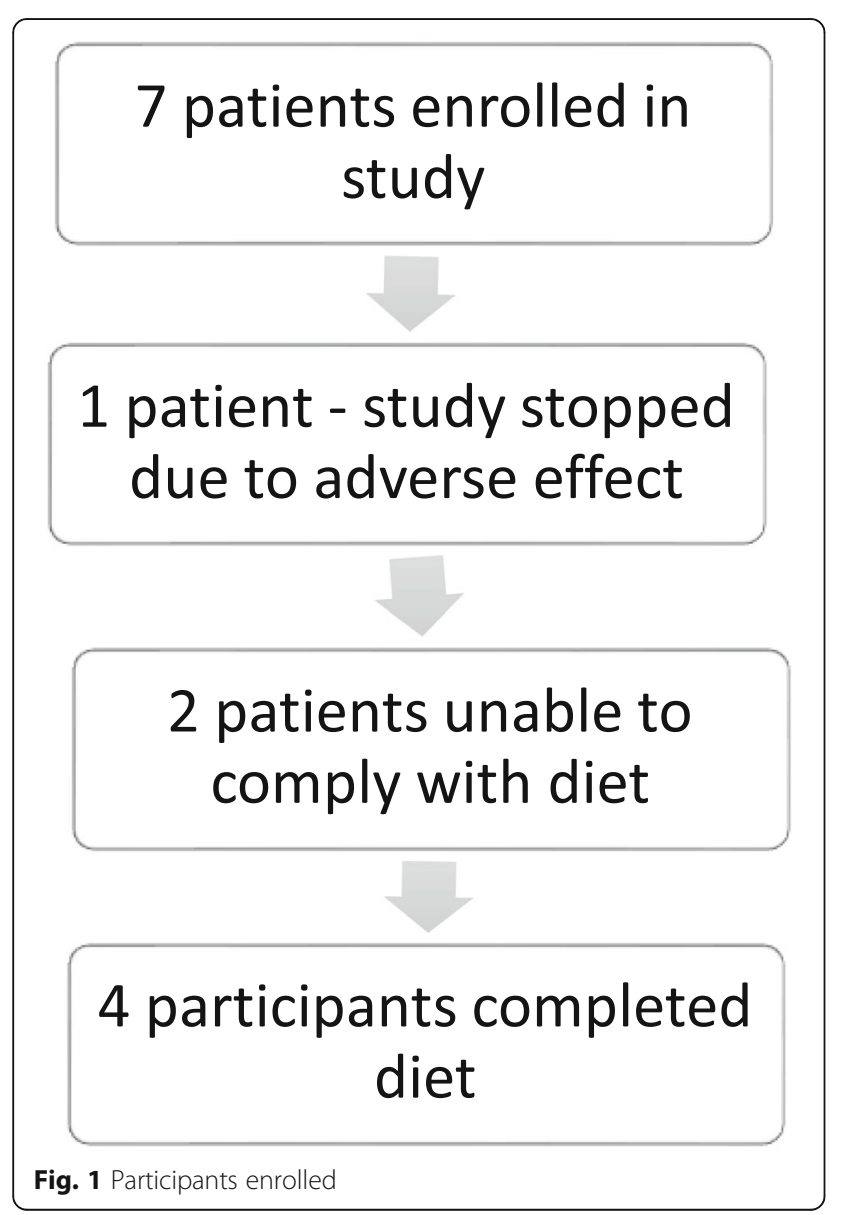

All participants were asked to stop at the 4 month period per the study protocol to assess post-diet changes. After this "off-diet" study period, all four families went back on the Modified Atkins Diet or at least some version of it, i.e. slightly higher allowable total carbohydrates.

\section{Weight}

Weight loss was not significant on the diet (see Fig. 2). Only one participant had a weight loss of $2.9 \mathrm{~kg}$ during the 4-month diet period. The remainder essentially maintained their weight. However, BMI z-scores improved for three out of the four participants, decreasing by average of 0.21 points for each participant. Weight gain was noted in all participants after the diet was stopped, especially the patient who did lose weight, almost in a rebound manner. Height curves were not negatively affected on the diet.

\section{Laboratory measures}

Blood work was checked at baseline, at the end of the diet period and 4 months off the diet. Three of four participants saw an increase of LDL, reflected in total cholesterol level as well. Triglycerides were overall stable; one participant saw a $39 \mathrm{mg} / \mathrm{dl}$ decrease in triglycerides.

Regarding markers of metabolic syndrome, Hemoglobin A1C values decreased in 3 out of 4 participants. Homeostasis model assessment of insulin resistance (HOMA-IR) scores were calculated using fasting insulin and glucose levels [17]. Impact on the diet on these scores were variable; one participant saw a profound drop in their HOMA-IR score; in the others, it was either stable or increased. None of the participants had elevated liver enzymes at baseline and these levels remained unchanged with the diet as noted.

Urine calcium/creatinine levels were normal for all participants at the end of the diet period and urinalyses did not demonstrate any crystals or red blood cells for any participant except for the one patient that the study protocol was stopped for due to urinalysis abnormalities (Table 2). 


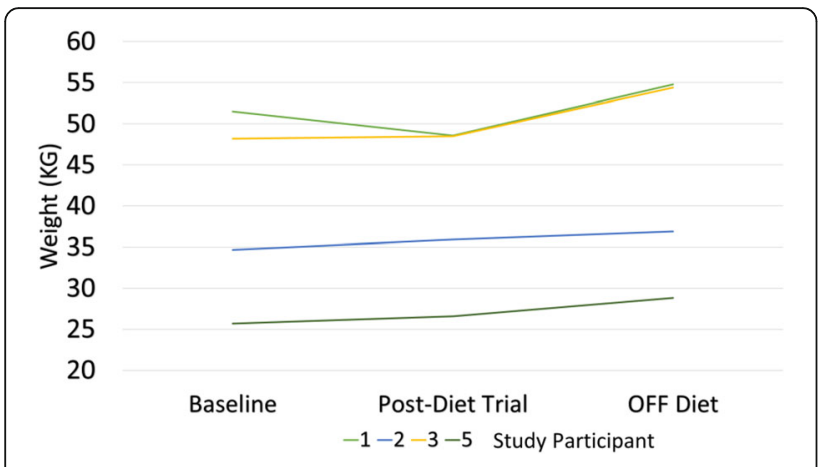

Fig. 2 Weight Changes of Participants on and off Diet

Table 2 Laboratory Measures in Pre and Post-Diet Checks

\begin{tabular}{|c|c|c|c|c|c|c|}
\hline Participant No. & 1 & 2 & 3 & $\begin{array}{l}4 \text { (excluded } \\
\text { Abnl urine) }\end{array}$ & 5 & 6 (Dropped) \\
\hline \multicolumn{7}{|c|}{ Total Cholesterol (mg/dl) } \\
\hline Pre-Diet & 147 & 181 & 197 & 142 & 156 & 116 \\
\hline Post-Diet & 136 & 211 & 223 & & 296 & \\
\hline Difference & -11 & 30 & 26 & & 140 & \\
\hline \multicolumn{7}{|l|}{ LDL (mg/dl) } \\
\hline Pre-Diet & 73 & 98 & 112 & 80 & 97 & 55 \\
\hline Post-Diet & 59 & 135 & 131 & & 235 & \\
\hline Difference & -14 & 37 & 19 & & 138 & \\
\hline \multicolumn{7}{|c|}{ Triglycerides (mg/dl) } \\
\hline Pre-Diet & 57 & 29 & 103 & 37 & 81 & 72 \\
\hline Post-Diet & 59 & 42 & 64 & & 80 & \\
\hline Difference & 2 & 13 & -39 & & -1 & \\
\hline \multicolumn{7}{|c|}{ Hemoglobin A1C } \\
\hline Pre-Diet & 5.2 & 4.8 & 6 & 4.9 & 5.6 & 5.8 \\
\hline Post-Diet & 4.8 & 4.8 & 5.7 & & 4.9 & \\
\hline Difference & -0.4 & 0 & -0.3 & & -0.7 & \\
\hline \multicolumn{7}{|c|}{ HOMA-IR Score* } \\
\hline Pre-Diet & 2.8 & 0.8 & 12.1 & 7.42 & 2.1 & 18.4 \\
\hline Post-Diet & 3.8 & 1.9 & 5 & & 2.3 & \\
\hline Difference & 1 & 1.1 & -7 & & 0.2 & \\
\hline \multicolumn{7}{|l|}{ ALT ( $\mathrm{nl}<31 \mathrm{IU})$} \\
\hline Pre- Diet & 14 & 20 & 16 & 28 & 13 & 12 \\
\hline On-Diet & 14 & 32 & 14 & & 26 & \\
\hline Post-Diet & 14 & 17 & 16 & & 10 & \\
\hline \multicolumn{7}{|c|}{ Urine $\mathrm{Ca} / \mathrm{Cr}$ Ratio $(\mathrm{nl}<0.2)$} \\
\hline Pre-Diet & 0.065 & 0.12 & 0.065 & 0.60 & 0.06 & $\mathrm{n} / \mathrm{a}$ \\
\hline On Diet & 0.089 & 0.16 & 0.031 & & 0.16 & \\
\hline Post-Diet & 0.01 & $\mathrm{n} / \mathrm{a}$ & 0.057 & & $\mathrm{n} / \mathrm{a}$ & \\
\hline
\end{tabular}

*HOMA-IR score above 1.9 - early insulin resistance; score above 2.9significant insulin resistance

Abbreviations: $m g$ milligrams, $d l$ deciliter, $I U$ international units

\section{Discussion}

This is the first prospective clinical study on a lowcarbohydrate diet for children with Prader-Willi Syndrome. Compliance to the diet was difficult for two out of seven of our participants, but the remainder found the MAD very feasible. Families reported several challenges to implementing a high-fat/low-carbohydrate diet including necessary meal planning, accommodations at school or needing to pack lunch, garnering acceptance and support from others caring for the child and others in the home (ex. siblings), and the increased financial cost of a high-fat/low-carbohydrate diet.

All four participants that completed the diet had weight stabilization or weight loss. In the off-diet period, weight gain velocity was noted to be increased. Thus, weight stabilization in this typically hyperphagic population can be seen as a positive outcome.

Three out of four of the participants who completed the diet had a significant elevation in their total cholesterol and LDL. This was an expected finding based on larger studies of patients on the modified atkins diet. Cervenka et al., found that among adult patients with epilepsy on the MAD, total cholesterol and LDL increased in the first 3 months and then normalized after 1 year on the diet [18]. A recent study on children with epilepsy on the ketogenic diet demonstrated that although LDL and triglycerides increase on the diet, carotid intima-media thickness and other markers of elasticity of the carotid artery and aorta does not worsen on a high-fat, low-carbohydrate diet [19, 20]. Further longterm studies are needed to establish cardiovascular safety of this diet due to potential benefits for a variety of conditions.

Two out of the seven participants in this small sample had an adverse effect: hypercalciuria and significant hyperlipidemia, respectively. These adverse effects had no clinical effects and resolved off the diet. However, this underlines that patients undertaking this diet for its possible beneficial effects should be followed by a medical team. There was no worsening constipation reported among study participants. No other adverse effects were seen during the diet period.

Limitations of the study include small sample size. Studies looking at diet are inherently difficult due to lack of precise control of actual dietary intake. We asked parents to report participants' weekly urine ketone checks but to improve accuracy of compliance, we could ask parents to send photos of the urine stick, for example.

\section{Conclusions}

Compliance to restrictive diets can be challenging for children and more so for children with PWS who may be sneaking in food. Additionally, there is likely an aspect of the Hawthorne effect: parents and children both 
know they are on a diet that is claimed to improve hyperphagia, satiety, behavior and help with weight loss so may report those effects greater than may actually exist. Also, families who had already implemented strict dietary measures to manage their child's Prader-Willi Syndrome were more likely to join the study and comply with the diet, an inherent selection bias. As more patients with Prader-Willi Syndrome implement this diet, this small pilot study demonstrates justification for larger multi-center studies.

\section{Acknowledgements}

The authors wish to acknowledge the generous support of the Foundation for Prader-Willi Syndrome Research, Canada, and the National Institutes of Health as well as the families of individuals with Prader-Willi Syndrome.

\section{Ethic approval and consent to participate}

Ethics approval obtained from Johns Hopkins School of Medicine IRB. Consent obtained from each study participant's parent; assent obtained from each pediatric participant.

\section{Authors' contributions}

$A S, E K, B B, G F$ and EG contributed to concept design and preparation of the manuscript. GF, CK, BB, EG participated in data collection. The author(s) read and approved the final manuscript.

\section{Authors' information}

Grace Felix- Pediatric Specialists of Virginia/INOVA Children's Hospital. Eric Kossoff- Department of Pediatric Neurology, Johns Hopkins School of Medicine. Bobbie Barron- Johns Hopkins School of Medicine. Caitlin KrekelJohns Hopkins School of Medicine. Elizabeth Getzoff Testa- Mount Washington Pediatric Hospital, Ann Scheimann- Johns Hopkins School of Medicine.

\section{Funding}

Foundation for Prader-Willi Research, Canada and NIH T32 Grant Funding for Salary Support for G. Felix Acknowledgements: AS, EK, BB, GF and EG contributed to concept design and preparation of the manuscript. GF, CK, BB, EG participated in data collection

\section{Availability of data and materials}

Supporting data is available for review upon request.

\section{Consent for publication}

We give consent to publish this report and consent to share data and materials.

\section{Competing interests}

The authors declare that they have no competing interests.

\section{Author details}

${ }^{1}$ Division of Pediatric Gastroenterology and Nutrition, Johns Hopkins School of Medicine, Baltimore, MD, USA. ${ }^{2}$ Pediatric Specialists of Virginia/INOVA Children's Hospital, Fairfax, Virginia, USA. ${ }^{3}$ Department of Pediatric Neurology, Johns Hopkins School of Medicine, Baltimore, MD, USA. ${ }^{4}$ Institute of Clinical and Translational Research, Johns Hopkins School of Medicine, Baltimore, MD, USA. ${ }^{5}$ Department of Psychology, Center for Pediatric Weight Management \& Healthy Living, Mt. Washington Pediatric Hospital, Baltimore, MD, USA. ${ }^{6}$ Division of Pediatric Gastroenterology and Nutrition, Johns Hopkins Hospital, 600 N. Wolfe Street Brady 320, Baltimore, MD 21287-2631, USA.
Received: 26 November 2019 Accepted: 18 May 2020

Published online: 03 June 2020

\section{References}

1. Prader A, Labhart A, Willi H. Ein Syndrome von Adipositas, Kleinwuchs, Kryptochismus und Oligophrenie nach myatonieartigem Zustand in Neugeborenenalter. Schweiz Med Wochenschr. 1956;86:1260-1.

2. Kimonis VE, Tamura R, Gold JA, et al. Early diagnosis in Prader-Willi syndrome reduces obesity and associated co-morbidities. Genes (Basel). 2019;10(11):898.

3. Bittel DC, Butler MG. Prader-willi syndrome: clinical genetics, Cytogenetics and molecular biology. Exp Rev Mol Med. 2005;7:1-20

4. Butler MG, Hanchett J, Thompson T. Clinical findings and natural history of Prader-willi syndrome. In: Butler MG, PDK L, Whitman BY, editors. Management of Prader-willi Syndrome. 3rd ed: Springer-Verlag; 2006. p. 348

5. Bistrian BR, Blackburn GL, Stanbury JB. Metabolic aspects of a protein sparing modified fast in the dietary Management of Prader-willi Obesity. NEJM. 1977;296:774-9.

6. Collier SB, Walker WA. Parenteral protein-sparing modified fast in an obese adolescent with Prader-willi syndrome. Nutrition Rev. 1991;49:235-8.

7. Messersmith NV, Slifer KJ, Pulbrook-Vetter V, Bellipanni K. Interdisciplinary behavioral intervention for life threatening obesity in Prader-willi syndrome. J Dev Behav Pediatr. 2008:29:129-34.

8. Schmidt Bonfig W, Dokoupil K, Schmidt H. A Special Strict, Fat-Reduced, Carbohydrate-Modified Diet Leads to Marked Even in Overweight Adolescents with Prader-willi Syndrome. Scien World Jour. 2009;14:934-9.

9. Marlowe M, Medeiros DM, Errera J, Mederios LC. Hair minerals and diet of Prader-Willi syndrome youth. J Autism Dev Disab. 1987;17:365-74

10. Hoffman C, Aultman D, Pipes P. A nutrition survey of and recommendations for individuals with Prader-willi syndrome who live in group homes. J Am Diet Assoc. 1992;92:823-33.

11. Stadler DD. Nutritional Management in Greenswag LR. In: Alexander RC editor. Management of Prader-willi Syndrome 2nd edition; 1995.

12. Balko K. Red yellow green system for weight management. Ontario PraderWilli Syndrome Association.

13. Kossoff EH, McGrogan JR, Bluml RM, Pillas DJ, Rubenstein JE, Vining EP. A modified Atkins diet is effective for the treatment of intractable pediatric epilepsy. Epilepsia. 2006;47(2):421-4

14. Kossoff EH, Dorward JL. The modified Atkins diet. Epilepsia. 2008;49(Suppl 8):37-41.

15. Roehl K, Sewak SL. Practice paper of the academy of nutrition and dietetics: class and modified Ketogenic diets for treatment of epilepsy. J Acad Nutr Diet. 2017:117(8):1279-92.

16. TREND Community. Ketogenic Diet for Prader-Willi Syndrome. The Charlie Foundation for Ketogenic Therapies. Published:2016.

17. Matthews DR, Hosker JP, Rudenski AS, Naylor BA, Treacher DF, Turner RC. Homeostasis model assessment: insulin resistance and beta-cell function from fasting plasma glucose and insulin concentrations in man. Diabetologia. 1985;28:412-9.

18. Cervanka MC, Patton K, Eloyan A, Henry B, Kossoff E. The impact of the modified Atkins diet on lipid profiles in adults with epilepsy. Nutr Neurosci. 2016:19(3):131-7.

19. McDonald TJW, Ratchford EV, Henry-Barron BJ, Kossoff EH, Cervanka MC. Impact of the modified Atkins diet on cardiovascular health in adults with epilepsy. Epilepsy Behav. 2018;29:82-6.

20. Ozdemir R, Guzel O, Kucuk M, Karadeniz C, Katipoglu N, Yilmaz U, Yilmazer MM, Mese T. The effect of the ketogenic diet on the vascular structure and functions in children with intractable epilepsy. Pediatr Neurol. 2016:56:30-4.

\section{Publisher's Note}

Springer Nature remains neutral with regard to jurisdictional claims in published maps and institutional affiliations. 